engagement benchmarks and evaluation criteria, at a macro and organisational level, in terms of the quality, quantity and timeliness of engagement programs and policies.

While research suggests that our traditional modes of community engagement and dissemination (community reports, feedback sessions and seminars) are our most effective tools in the array of knowledge transfer techniques $^{6}$, community engagement and knowledge transfer are dynamic and adaptive processes. Taking stock of existing processes and emerging opportunities ensures the stability of stakeholder relationships and augments the effectiveness of dissemination strategies. The quality of research output is heightened when stakeholders have a central place in the generation of knowledge and understanding. Knowledge transfer, in its simplest sense, is the feedback mechanism in an economy of knowledge powered by engagement and collaboration.

\section{REFERENCES}

1. Kippax S, Kinder P. Reflexive practice: The relationship between social research and health promotion in HIV prevention. Sex Education 2002; 2: 91-104.
2. Kippax S, Connell RW, DowsettGW, Crawford J. Sustaining safe sex: Gay communities respond to AIDS. London: Falmer Press, 1993.

3. Mitchell A, Wals J. The community model of research transfer. In Lin V, Gibson B, editors Evidence-based health policy: Problems and possibilities. Melbourne: Oxford University Press, 2003: 263-71.

4. Black N. Evidence based policy: Proceed with care. British Medical Journal 2001; 323: 275-9.

5. National Health and Medical Research Council. A model framework for consumer and community participation in health and medical research. Canberra: NHMRC, 2005. Available at www.nhmrc.gov.au/publications/synopses/ r22syn.htm.

6. Del Santo T, Goldberg S, Choice P. Exploratory research in public social service agencies: An assessment of dissemination and utilization, Journal of Sociology and Social Welfare 2002; 24(4): 59-81.

7. Barnett K, Hattis P. Toward a more strategic approach to community engagement: A commentary. Journal of Health and Human Services Administration 2002; 25: 204-14.

8. Cameron R, Brown KS, Best A.J. The dissemination of chronic disease prevention programs: Linking science and practice. Canadian Journal of Public Health 1996, 87(S2), S50-S53. 露

\title{
IMPROVING SUN PROTECTION BEHAVIOUR THROUGH EVIDENCE-BASED CAMPAIGNS
}

\author{
Sandra Jones, Lyn Rees, Keryn Johnson \\ Centre for Health Behaviour and \\ Communication Research \\ University of Wollongong
}

\section{Anita Tang}

The Cancer Council New South Wales

Australia has the highest incidence of skin cancer in the world. Skin cancer is the most common form of cancer in Australia, with incidence rates outnumbering all other forms of cancer by more than three to one. The Australian health system spends more money on the diagnosis and treatment of skin cancer than on any other cancer, an estimated $\$ 420 \mathrm{~m}$ each year. ${ }^{1}$ The majority of these skin cancers could be prevented if the public could be persuaded to adequately protect themselves from the sun.

Social marketing is well placed to guide the development of sun protection programs, as it is orientated to achieving voluntary behaviour change at a group or community level. It is a knowledge discipline grounded in behavioural and communications theory that has developed from commercial marketing, with an underlying difference of being driven by a motivation to change consumer behaviour for the social or individual 'good', rather than for company profit. ${ }^{2}$ An understanding of the theory and practice of social marketing provides a foundation for the development of communication campaigns aimed at changing the community's health-related behaviour. However, many organisations that conduct communication campaigns do not adequately consider these factors in the development of their campaigns.

Social marketing has been used in the areas of smoking cessation, healthy eating, drug use and physical activity promotion. It has been used to a lesser extent for primary prevention of skin cancer. ${ }^{3}$ As a result, there is no documented evidence on how best to utilise social marketing within sun protection campaigns. In a specific application to sun protection, this project will investigate the use of social marketing and advertising communications theory in practice, and systematically apply the theory and research in the development of a demonstration campaign by the Cancer Council New South Wales.

This paper reports on work-in-progress and presents the proposed methodology and the results achieved in the first nine months of a three-year project. 


\section{METHOD AND RESULTS TO DATE}

\section{Phase one-Formative research}

1. Identification of the use of relevant theory in sun protection research and practice

The project commenced with a literature search to identify research on the use of social marketing and advertising communications theory and strategies to develop and conduct primary prevention campaigns that have potential for use within sun protection campaigns. This has provided a framework with which to analyse past and present sun protection programs via the systematic review and in-depth analysis of communication strategies.

\subsection{Systematic review of sun protection primary prevention programs}

A series of systematic reviews will be undertaken on published and unpublished primary prevention programs that have been implemented over the past 25 years. The reviews will examine the extent of use of social marketing and communication theory in practice within sun protection programs, and identify effective elements within these programs.

Preliminary analysis of 21 published studies targeted at children and their sun protection behaviours (utilizing pre and post designs with comparison groups) has confirmed low utilisation of social marketing within past programs. The analysis revealed only one program where it was stated that a social marketing process had been used in the program's development. However, other elements that sit within the social marketing framework (such as the use of behavioural theory and formative research, the targeting of secondary audiences and the utilization of environmental changes to facilitate behaviour change) were used within many of the interventions. The combination of these elements appeared to produce effective outcomes, though increased effectiveness could not be predicted following the use of any one element.

No studies reported segmentation of the target audience or discussed tailoring of messages for specific subgroups within the larger target group. These approaches could be useful in sun protection campaigns because if the target market is segmented into smaller, more homogenous groups, sun protection messages can be tailored to address the attitudes and perceptions of the group and to appeal more specifically to them. Also, while research studies on specific message factors for sun protection are evident on literature review, little of this research appears to have been utilised within programs to date. Further work will broaden inclusion criteria and commence systematic review on interventions targeting adolescents and adult populations.

\subsection{In-depth analysis of sun protection communication campaigns}

An in-depth analysis will be undertaken of recent (in the past five years) sun protection communication campaigns from Australia, the United States, the United Kingdom and Canada that have completed impact or outcome evaluations. Within Australia, this will include campaigns currently conducted by the Australian Cancer Society, the state and territory Cancer Councils, government-funded organisations, and other non-profit cancer organisations. International campaigns will be those conducted by national or statewide cancer societies or public health organisations within the United States, Canada or the United Kingdom, dependent on the availability of campaigns materials. This analysis will specifically examine communication strategies used within these campaigns.

\section{Selecting and investigating the target audience}

2.1 Identification and review of literature to determine current knowledge and sun protection behaviour in the target markets

A comprehensive literature review will be conducted to examine current sun protection knowledge and behaviour, and particularly the effects of previous sun protection interventions on attitudes and behaviours in the Australian population. A preliminary review of current literature identified those segments of the population at risk of developing skin cancer, and current patterns of behaviour in relation to sun protection within these segments.

\subsection{Consultation with a panel of experts}

As part of broader project management processes, a project reference group was established to ensure expert consultation and participatory management decisionmaking. ${ }^{4}$ The group consisted of the Cancer Council New South Wales Chief Executive Officer and relevant experts from the Cancer Council in the areas of retail, marketing and communications, health strategy and campaigns, media and skin cancer prevention. The group also included experts from the University of Wollongong in marketing, social marketing and health behaviour, as well as the project manager and $\mathrm{PhD}$ students.

The format for the meeting utilised a clear goal-oriented agenda and an evidenced-based platform on which to base the discussion. A summary of the current literature was presented, detailing which segments of the population were at risk of developing skin cancer and which segments had modified their behaviour and adopted positive sun protection practices. A historical review of sun protection programs provided by the Cancer Council allowed reflection on which segments had previously been targeted and current priorities for the council. After reflecting on these presentations the group participated in a facilitated discussion in order to make a decision regarding the primary segmentation of the target market. Various established techniques were used to facilitate the discussion. These included brainstorming to generate all relevant variables and concept mapping to draw out a consensus regarding the variables discussed. ${ }^{5}$

Results from this process include a decision by the group to use age as the primary segmentation criteria for the target 
market (because the risk factors and behaviours in skin cancer prevention vary predominantly by age). ${ }^{6}$ Additional demographic variables would be considered as secondary segmentation variables and would be further explored as part of formative research with the target market. This is consistent with the findings of Kotler, Lee and Roberto, who describe how target audience segmentation often uses one primary basis to segment a market, with each segment then 'further profiled and perhaps narrowed, by using additional important and relevant variables that predict response to strategies'. ${ }^{7}$

\subsection{Determining the effects of previous sun protection} within the target market

Consistent with the principle of market segmentation, qualitative and quantitative research will be undertaken with the target market. Likely areas of investigation include perceived susceptibility to skin damage, perceived severity of sun damage, attitudes towards tanning, and the influence of family and friends on sun protection behaviours.

\section{Phase two-Application of formative research}

Development of best-practice guidelines and a comprehensive sun protection campaign

A detailed set of guidelines for the development and implementation of sun protection campaigns will be developed from the results of Phase one. The research team will also develop a comprehensive social marketing plan for a sun protection campaign for the Cancer Council. The content of this plan will incorporate the best-practice guidelines and formative research. This plan will focus on the four key elements of marketing campaigns - product, price, place and promotion-and will include elements from advertising theory such as communication objectives and positioning, execution tactics, and media strategy. It is hoped that further funding will be secured to evaluate the implementation and outcomes of this campaign.

\section{DISCUSSION}

While social marketing processes have rarely been used in sun protection campaigns, the preliminary work undertaken has shown that social marketing offers a useful framework that can accommodate elements already used within campaigns, as well as adding other elements that could lead to improved effectiveness. Areas relating to behavioural and communication theory appear under-developed in many sun protection programs, with little use of segmentation on attitudinal or behavioural grounds, and minimal attention to message factors within the programs reviewed. This gap between theory and practice is important to address. In the next stage of our project, we will identify how these elements can be best incorporated into the planning and development of campaigns.

The project processes described in this paper demonstrate how appropriate formative research (such as literature reviews) can combine with established project management processes to provide a platform for evidence-based decisionmaking. This paper also describes the establishment of the first comprehensive attempt to investigate the extent to which the academic theory (social marketing and advertising communications) can be applied in practice to develop and implement a social marketing sun protection campaign. This campaign will, in turn, inform future primary prevention interventions by demonstrating how best to close the gap between theory and practice.

\section{REFERENCES}

1. Australian Institute of Health and Welfare and Australasian Associations of Cancer Registries. The 2002 national nonmelanoma skin cancer survey. A report by the National Cancer Control Initiative. Non-melanoma Skin Cancer Working Group. Melbourne, National Cancer Control Initiative, 2003.

2. Kotler P, Roberto EL. Social marketing: Strategies for changing public behavior. New York: Free Press, 1989.

3. Peattie K, Peattie S, et al. Skin cancer prevention: Reevaluating the public policy. Journal of Public Policy and Marketing 2001. 20(2): 268-79.

4. Hanna MS, Wilson GL. Communicating in business and professional settings. Fourth edition. New York: McGrawHill, 1998.

5. Antil T, Desrochers M, Joubert P, Bouchard C. Implementation of an innovative grant programme to build partnerships between researchers, decision-makers and practitioners: The experience of the Quebec Social Research Council. Journal of Health Services Research \& Policy 2003; 8: S35.

6. Buller D, Borland R. Skin cancer prevention for children: A critical review. Health Education \& Behavior 1999; 26(3): 317-43.

7. Kotler P, Roberto N, Lee N. Social marketing: Improving the quality of life. Sage Publications: California, 2002. 중 